\title{
Особенности диатомовых комплексов донных осадков малых водоемов депрессии озера Имандра
}

\author{
Косова А.Л. ${ }^{1}$, Денисов Д.Б. ${ }^{1}$, Николаева С.Б. ${ }^{2}$ \\ ${ }^{1}$ Институт проблем промышленной экологии Севера КНЦ РАН, Anamumbl,annkosova1976@yandex.ru \\ ${ }^{2}$ Геологический институт КНЦ РАН, Anamumbl, nikolaeva@geoksc.apatity.ru
}

Аннотация. Выполнено исследование диатомовых комплексов в донных отложениях 2-х малых безымянных озер на западном побережье озера Имандра (Мурманская область). Описаны особенности исторической динамики диатомовой флоры в ответ на изменения окружающей среды и климата в голоцене. Таксономический состав диатомей исследованных водоемов характеризуется значимыми различиями: в одном обнаружено 72, а в другом 205 таксонов диатомей рангом ниже рода. В обоих водоемах наиболее богаты видами роды Eunotia и Pinnularia, что типично для мелководных ацидных водоемов. Диатомовый анализ позволил выявить последствия тектонической активности в зоне Имандровской депрессии, сопровождающиеся резким повышением уровня воды, что подтверждается литологическими данными.

Ключевые слова: донные отложения, диатомовые водоросли, голоцен, Имандровская депрессия, сейсмичность.

\section{Features of diatom complexes in bottom sediments of the Imandra depression small lakes}

\author{
Kosova A.L. ${ }^{1}$, Denisov D.B. ${ }^{1}$, Nikolaeva S.B. ${ }^{2}$ \\ ${ }^{1}$ Institute of the North industrial ecological problems, KSC RAS, Apatity, annkosova1976@yandex.ru \\ ${ }^{2}$ Geological institute KSC RAS, Apatity, nikolaeva@geoksc.apatity.ru
}

\begin{abstract}
The study of diatom complexes in the bottom sediments of 2 small nameless lakes on the western coast of Imandra Lake (Murmansk region) is carried out. The features of the historical dynamics of diatom flora in response to changes in the environment and climate in the Holocene are described. The taxonomic composition of the diatoms of the studied water bodies is characterized by significant differences: in the 1 st one, 72 were found, and in the second one, 205 diatom taxons with a rank lower than the genus. In both reservoirs, the species Eunotia and Pinnularia are the most rich in species, which is typical of shallow-water acidic reservoirs. Diatom analysis revealed the effects of tectonic activity in the area of the Imandra Lake depression, accompanied by a sharp increase in the water level, which is confirmed by lithological data.
\end{abstract}

Key words: sediments; diatoms; Holocene; Imandra Lake; seismicity.

\section{Введение}

Комплексная оценка современного состояния и долговременной динамики арктических пресноводных экосистем в условиях глобальных и региональных изменений окружающей среды невозможна без знаний исторического формирования экологических условий на протяжении позднего плейстоцена и голоцена. Огромное значение для палеоэкологических реконструкций в высоких широтах имеет диатомовый анализ донных отложений. В настоящее время диатомовый анализ входит в группу руководящих методов, применяемых для реконструкции исторической динамики окружающей среды и климата. В последние десятилетия остро обозначились новые вызовы - современные глобальные климатические изменения, которые происходят быстрее и масштабнее в высоких широтах. Поэтому палеоэкологические исследования с применением диатомового анализа приобрели особую актуальность. Озеро Имандра - крупнейший пресноводный водоем Северо-Запада РФ, расположенное за полярным кругом. Изучению плейстоцен-голоценовых изменений палеогеографических обстановок в бассейне озера Имандра посвящен ряд исследований (Рихтер, 1934; Арманд и др., 1969; Арманд, Самсонова, 1969; Рубинраут, Каган, 1975; Николаева и др., 2015, 2016; Толстоброва и др., 2016 и др.). В то же время, выявление основных исторических этапов развития и трансформации экологических условий бассейна оз. Имандра требуют новых знаний о видовом составе, эко- 
логических особенностях и долговременной динамике диатомовых комплексов донных отложений.

Цель нашей работы - выявление особенностей структуры диатомовых комплексов в донных отложениях двух малых озер, расположенных в депрессии озера Имандра, и выявление основных этапов и тенденций их развития в позднем плейстоцене и голоцене, как основы для понимания экологических условий формирования качества вод и процессов седиментации.

\section{материалы и методы}

Материалом для анализа послужили донные отложения из двух малых озер, расположенных на плоской заболоченной территории в 0.4-1.3 км от Уполокшской губы озера Имандра. Отбор донных осадков производился в летний период с катамарана при помощи переносного отечественного поршневого бура, по схеме, описанной ранее (Николаева и др., 2015). На диатомовый анализ из озера 1 отобрано 9 образцов с интервалом 5 см, из озера 2-16 образцов с интервалами 7-10 см. Диатомовый анализ донных отложений был проведен по стандартной общепринятой методике (Давыдова, 1985; Денисов, 2007), по схеме, принятой в ИППЭС КНЦ РАН (Косова и др., 2011).

\section{Результаты и обсуждения}

Подробное описание литологического строения разрезов донных отложений исследуемых озер описано в работе С.Б. Николаевой (Николаева и др., 2015). В озере 1 с выс. отм. 148.8 м над уровнем моря (н.у.м.) бурением вскрыта ненарушенная последовательность осадков (рис. 1). В озере 2 с выс. отм. 133.4 м н.у.м. впервые выделена сейсмогенная фация (брекчиевый горизонт) (рис. 2).

В озере 1 обнаружено 72 таксона в 22 родах. Наибольшее таксономическое разнообразие отмечается в родах Eunotia (17), Pinnularia (12), Gomphonema (8), Brachysira (6).

На протяжении всей толщи донных отложений из озера 1 в составе диатомовых комплексов (ДК) преобладают виды, характерные для болот и дистрофных озер: Frustulia rhomboides (Ehrb.) De

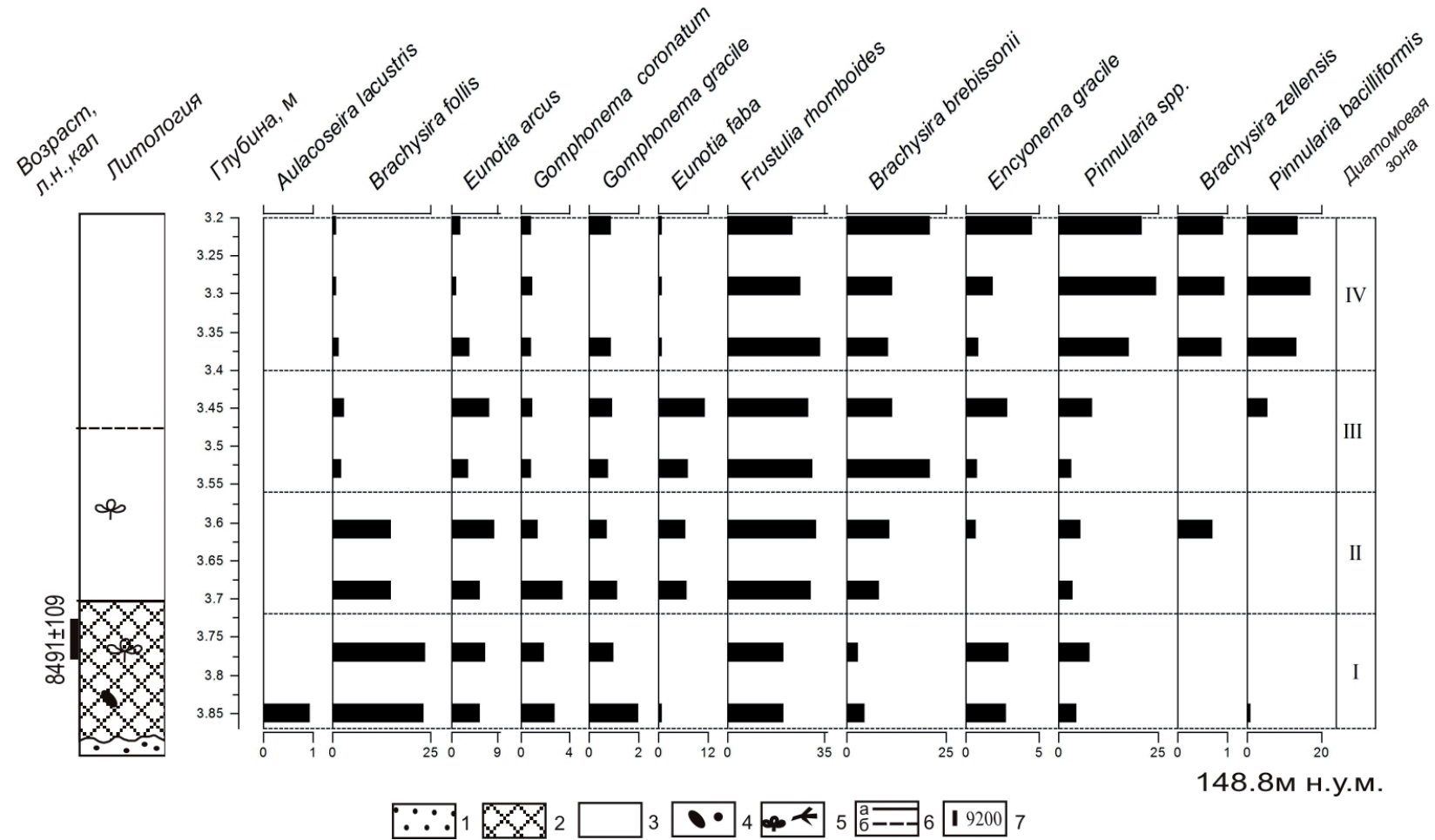

Рис. 1. Разрез донных отложений и диатомовая диаграмма массовых и индикаторных видов (\%) осадков озера 1. 1 - песок, 2 - смесь торфа, гиттии и песка, 3 - гиттия, 4 - зерна гравия, 5 - макроостатки растений, 6 - контакты резкие (а), постепенные (б), 7 - места отбора проб на $\mathrm{C}^{14}$.

Fig.1. Lithology and diatom diagram of mass and indicator species (\%) of Lake 1 sediments. 1 - sand, 2 - mixture of peat, sand, gyttja and redeposited plant residues, 3 - gyttja, 4 - gravel, 5 -fragments: plant (a), wood (b), 6 - contacts: abrupt (a), gradational (b), 7 - radiocarbon dating. 


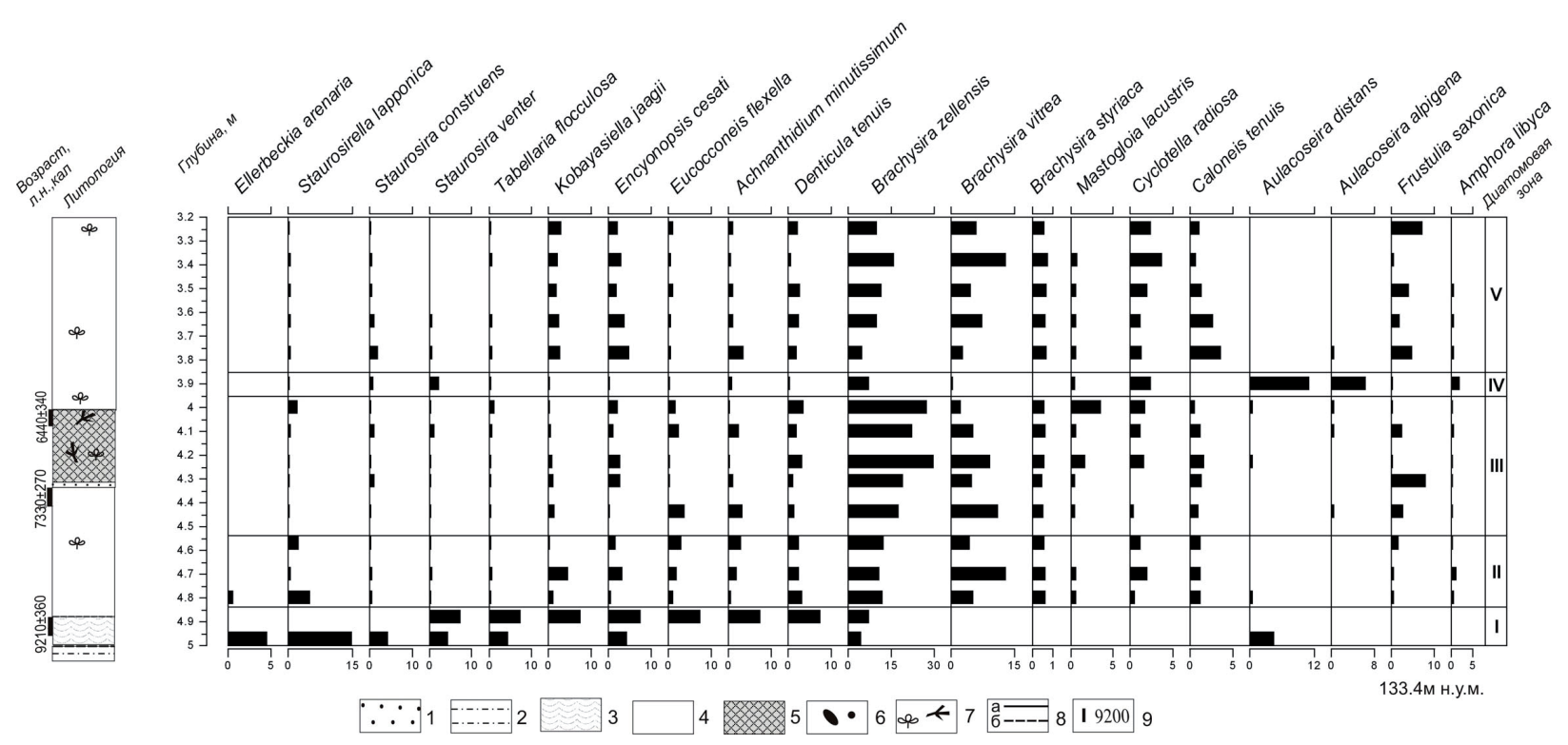

Рис. 2. Разрез донных отложений и диатомовая диаграмма массовых и индикаторных видов (\%) осадков озера 2. 1 - песок, 2 - алеврит, 3 - гиттия опесчаненная, 4 - гиттия, 5 - аномальный «брекчиевый» горизонт, 6 - зерна гравия, 7 - макроостатки растений и древесины, 7 - контакты резкие (а), постепенные (б), 8 - места отбора проб на $\mathrm{C}^{14}$.

Fig. 2. Lithology and diatom diagram of mass and indicator species (\%) of Lake 2 sediments 1 - sand, 2 - silt, 3 - sandy gyttia, 4 - gyttja, 5 - breccias horizon, 6 - gravel, 7 - fragments: plant and wood, 8 - contacts: abrupt (a), gradational (b), 9 - radiocarbon dating.

Toni (20-34 \%), представители родов Brachysira (Brachysira follis (Ehrb.) R.Ross in Hartley (23-1 \%), B. brebissonii R.Ross (3-21 \%)), Eunotia (9.5-27.6 \%) и Pinnularia (3-25 \%). Диатомовая флора представлена типичными пресноводными таксонами. На долю бентосных видов приходится до 93 \% от общего числа створок. Анализ соотношения диатомового сообщества по галобности вверх по разрезу указывает на уменьшение доли галофобов (64-41 \%) и увеличение доли индифферентных форм (32-41 \%). В структуре видов по географической приуроченности наблюдаются изменения от нижних слоев к верхним: виды-космополиты, составляющие до 58 \% в нижних слоях, уступают место арктоальпийским видам. Реконструированное значение $\mathrm{pH}$ составляет 6.6.

Изменения видового состава и структуры ДК по разрезу позволили выделить четыре диатомовые зоны (ДЗ) (рис. 1). Характер и динамика изменений диатомовой флоры позволяют сделать вывод, что озеро сформировалось на заболоченном участке в начале атлантического периода, а затем происходило постепенное сокращение его площади и глубины. Судя по характеру ДК, отложения накапливались в холодном мелководном олиготрофном водоеме, со слабокислой средой. Границы между ДЗ отражают смену экологических условий обитания диатомей, при этом в седиментах не наблюдается резких литологических границ.

В отложениях из озера 2 было обнаружено 205 таксонов диатомей рангом ниже рода (в 49 родах). Наибольшего таксономического разнообразия достигают представители родов Eunotia (16), Pinnularia (15), Cymbella (14), Navicula (13), Gomphonema (10).

Состав ДК из ДО озера 2 существенно отличается от флоры озера 1. На протяжении всей толщи ДО, кроме двух образцов с глубины 5-4.97 м и 4-3.83 м преобладают бентосные формы. По составу ДК было выделено пять ДЗ (рис. 2).

Д3 I (интервал 5-4.83 м) характеризует начальный этап формирования водоема. В образце 5-4.97 м доминанты представлены Staurosirella lapponica (Grun.) D.M.Williams \& Round (18 \%). В роли сопутствующих видов выступают Staurosira venter (Ehrb.) H.Kobayasi, S. construens Ehrb., Ellerbeckia arenaria (Moore ex Ralfs) R.M.Crawford, Aulacoseira distans (Ehrb.) Simons., виды рода 
Cyclotella. Основу диатомовых ассоциаций составляют бентосные и планктонно-бентосные формы. Возможно, на данном этапе развития водоем представлял собой залив палео-Имандры или мелководное озеро олиготрофного типа со значениями $\mathrm{pH}$ близким к нейтральным.

ДЗ ІІ (интервал 4.83-4.57 м) отличается резким увеличением концентрации диатомей в отложениях (до 71-153 млн. ств./г) и таксономического разнообразия (73-92 вида в образцах). Доминируют бентосные виды: Brachysira zellensis, B. vitrea. Суммарная численность видов рода Cусlotella колеблется в пределах 1.7-4.5\%. Отличительной особенностью ассоциаций является присутствие Mastogloia lacustris (Grun.) Grun. in van Heurck.

Д3 ІІІ (интервал 4.57-4.00 м). Отмечается значительное уменьшение общего обилия 22-44 млн. ств./Г. Видовое разнообразие соответствует 72-95 видам в образце. Основная доля, как в ДЗ ІІ, принадлежит бентосным формам. Доминантом является вид Brachysira zellensis (до 30 \%), субдоминантом -B. vitrea (до 9\%). Вид Mastogloia lacustris встречается единично, на глубине 4.06-4.00 м его доля достигает 3.7 \%. Образцы с глубины 4.47-4.44 м и 4.34-4.31 м отобраны из гиттии, а образцы 4.26-4.23 м, 4.13-4.10 м, 4.06-4.00 м из брекчиевого горизонта. При этом явных отличий видового состава и экологических характеристик диатомовых ассоциаций не выявлено.

Д3 IV (интервал 4.00-3.83 м) отображает значительные изменения уровня водоема. Доминирующий комплекс представлен планктонными видами Aulacoseira distans (Ehrb.) Simons. (11\%) и A. alpigena (Grun.) Kramm. (6.5 \%). Отмечается самое высокое таксономическое разнообразие, 120 видов в образце. Доля Brachysira zellensis составляет 7 \%. Отмечено присутствие Mastogloia lacustris. В структуре видов по географической приуроченности отмечается максимальное содержание бореальных видов (16\%).

Д3 V (интервал 3.83-3.25 м). ДК отражают снижение уровня водоема, доля планктонных форм снижается до 5 \%. Вверх по разрезу численность представителей рода Brachysira возрастает, занимая доминирующее положение в диатомовом сообществе. Присутствие Mastogloia lacustris не зафиксировано только в самом верхнем образце с глубины 3.28-3.25 м. Данные изменения отражает последовательное уменьшение глубины водоема, заболачивание его берегов.

Большой интерес представляет нахождение в составе олигогалобной флоры вида Mastogloia lacustris в осадках озера 2. Этот вид описывается как алькалифил и эвригалинный мезогалоб (Каган, 2012) и характерен для водоемов, отделившихся от моря. Присутствие Mastogloia lacustris зафиксировано с момента интенсивного накопления органики в первой половине атлантического периода до субатлантического периода. Следовательно, его появление в ДО озера не может быть связано с морской трансгрессией на данной территории. Mastogloia lacustris встречается в пресноводных водоемах, но чаще там, где выше минерализация или щелочная среда. Возможно, развитие данного вида происходило в результате изменения химического состава воды. Озеро расположено в зоне разломов и не исключено, что в него одновременно поступали как трещинные, так и поверхностные воды.

Озеро с выс. отм 133.4 м н.у.м. представляло собой сравнительно мелководный водоем до начала атлантического периода. Состав ДК из брекчиевого горизонта сходен с флорой из нижележащих слоев, что указывает на однородность условий окружающей среды. Резкое снижение общего обилия диатомей связано с поступлением огромного количества терригенного материала с водосборной площади. Богатая диатомовая флора и доминирование планктонных видов, характерных для более крупных озер, наблюдаемая в вышележащем слое, и их последующее исчезновение также свидетельствуют в пользу предположения, что такой характер нарушений вызван эрозией, перемещением и последующим переотложением осадков. Это могло быть связано с поднятием уровня оз. Имандра и заплеском большой волны со стороны озера на прилегающую низменность (Николаева и др., 2016) или иными тектоническими причинами.

Последовательное развитие диатомовой флоры и полное отсутствие планктонных видов в ДО озера 1 исключает влияние вод оз. Имандра. Следовательно, подъем воды в Имандре во время сейсмического события был ниже отметки, на которой располагается озеро 1. 


\section{Заключение}

Таким образом, выполненное исследование диатомовых комплексов в донных отложениях 2-х малых безымянных озер на западном побережье озера Имандра позволило установить, что диатомовые комплексы характеризуются существенными изменениями в ответ на динамику климатических и геологических факторов в голоцене. Таксономический состав диатомей близко расположенных малых водоемов различен: в одном обнаружено 72, а в другом 205 таксонов диатомей рангом ниже рода. В обоих водоемах наиболее богаты видами роды Eunotiau Pinnularia, что типично для мелководных ацидных водоемов. Диатомовый анализ позволил выявить последствия тектонической активности в зоне Имандровской депрессии, сопровождающиеся резким повышением уровня воды, что подтверждается литологическими данными. Присутствие в составе олигогалобной флоры вида Mastogloia lacustris в осадках озера 2 свидетельствует о повышенной минерализации воды в озере. Полученные результаты свидетельствуют о возможности использования диатомового анализа (наряду с другими методами и подходами) для выявления и изучения катастрофических процессов голоцена.

Работа выполнена при поддержке гранта РФФИ 18-05-60125 Арктика.

\section{Литература}

1. Арманд А.Д., Самсонова Л.Я. Морские отложения и голоценовая тектоника района Кандалакши // Основные проблемы геоморфологии и стратиграфии антропогена Кольского полуострова. Л. Изд-во: Наука. 1969. С. 96-111.

2. Арманд Н.Н., Евзеров В.Я., Гунова В.С., Лебедева Р.М. Палеогеография центральной части Кольского полуострова в голоцене // Основные проблемы геоморфологии и стратиграфии антропогена Кольского полуострова. Л. Изд-во: Наука. 1969. С. 80-85.

3. Давыдова Н.Н. Диатомовые водоросли - индикаторы природных условий водоемов в голоцене. Л. Издво: Наука. 1985. 244 с.

4. Денисов Д.Б. Изменения гидрохимического состава и диатомовой флоры донных отложений в зоне воздействия горнорудного производства (Кольский полуостров) // Водные ресурсы. 2007. Т. 34. № 6. С. 719-730.

5. Каган Л.Я. Диатомовые водоросли евро-арктического региона Аннотированная коллекция (древние и современные морские и пресноводные). Апатиты: Изд-во Кольского научного центра РАН. 2012. 209 с.

6. Косова А.Л., Малышева М.Б., Денисов Д.Б. К методике камеральной обработки проб для диатомового анализа донных отложений // Квартер во всем его многообразии. Фундаментальные проблемы, итоги изучения и основные направления дальнейших исследований: Материалы VII Всероссийского совещания по изучению четвертичного периода (г. Апатиты, 12-17 сентября, 2011 г.). В 2 т. / Рос.акад. наук, Отд. наук о Земле, Комиссия по изуч. четвертич. периода, Геологический ин-т КНЦ РАН. Апатиты. СПб. 2011. T. 1. (A-K). C. 294-295.

7. Николаева С.Б., Лаврова Н.Б., Толстобров Д.С., Денисов Д.Б.Реконструкция палеогеографических обстановок голоцена в районе озера Имандра (Кольский регион): результаты палеолимнологических исследований // Труды КарНЦ РАН. 2015. № 5. С. 34-47.

8. Николаева С.Б., Лаврова Н.Б., Денисов Д.Б., Толстобров Д.С.Следы катастрофических процессов в донных осадках озер западного побережья озера Бабинская Имандра (Кольский регион) // Изв. РГО. 2016. Т. 148. Вып. 4. С. 38-52.

9. Рихтер Г.Д. Физико-географический очерк озера Имандра и его бассейна. Л: Государственное техникотеоретическое издательство. 1934. Вып. 5. 144 с.

10. Рубинраут Г.С., Каган Л.Я. О формировании Верхнепонойской и Имандровской депрессий // История озер в голоцене. Тез. IV Всесоюз. симпозиумапо истории озер. Л. Изд-во: Ин-т озероведения АН СССР. 1975. C. $63-68$.

11. Толстоброва А.Н., Толстобров Д.С., Колька В.В., Корсакова О.П. История развития озера Осинового (Кольский регион) в поздне- и постледниковое время по материалам диатомового анализа донных отложений // Труды КарНЦ РАН. 2016. № 5. С. 106-116. 